\title{
Can the informal sector affect the relationship between unemployment and output? An analysis of the Mexican case
}

\author{
Alejandro Islas-Camargo and Willy W. Cortez ${ }^{1}$
}

\begin{abstract}
A key aspect of developing countries is the existence of a large informal sector. In the present paper, we analyse the effect of this feature on the relationship between unemployment changes and output growth for Mexico, a country characterized by the existence of a large informal sector. Following recent studies on Okun's coefficient, we first test whether the relationship between the cyclical components of unemployment and output is asymmetric. We then explore the possibility that this non-linear relationship may be affected by changes in the informal sector. Our results indicate that there is evidence of an asymmetric relationship between the cyclical components.
\end{abstract}

\section{Keywords}

Informal sector, labour mobility, unemployment, economic growth, mathematical models, case studies, Mexico

\section{JEL classification}

C34, E23, E24, E32

\section{Authors}

Alejandro Islas-Camargo is a full-time professor at the Department of Statistics of the Mexico Autonomous Institute of Technology (ITAM) in Mexico City. Email: aislas@itam.mx.

Willy W. Cortez is a professor and research fellow with the Department of Quantitative Methods (CUCEA) of the University of Guadalajara, Mexico. Email: wcortez@cucea.udg.mx.

\footnotetext{
1 The authors gratefully acknowledge comments made by participants at the CUCEA research seminar and Jaime Ros. Any remaining errors are the authors' exclusive responsibility. Alejandro Islas-Camargo wishes to acknowledge support from the Mexican Cultural Association and the Mexican National Council for Science and Technology (CONACYT) through its sabbatical scholarship. This study was prepared whilst Alejandro Islas-Camargo was visiting the Nepal Study Center of the Department of Economics and the RWJF Center for Health Policy at the University of New Mexico, United States.
} 


\section{Introduction}

One of the central relationships in macroeconomics, known as Okun's law, establishes the cost of unemployment in terms of output. ${ }^{2}$ Following Okun's (1962) seminal paper, early studies found that a 1 percentage point change in unemployment would cause a change of about 3 percentage points in output in the opposite direction. We now know that Okun's coefficient does not remain constant for a number of reasons, including changes in labour market institutions and technological and demographic changes. ${ }^{3}$

In a recent study for a group of 71 developed and developing countries, Ball and others (2016) find that unemployment is less sensitive to output fluctuations in developing economies than in developed ones. More specifically, they find that Okun's coefficient is about half as large on average in developing economies as in advanced economies. These authors further note that the literature has identified several factors that can help explain the difference in the responsiveness of unemployment to output fluctuations between these two types of economies.

One of these factors is the size of the shadow economy or informal sector. ${ }^{4}$ In their cross-sectional analysis, these authors find some evidence that the existence of the informal sector affects the relationship between the formal labour market and measured output: the larger the informal sector, the smaller the Okun's coefficient. Dell'Anno and Solomon (2008) found that the informal sector reduced the size of Okun's coefficient even in large economies like the United States. One drawback of their study, however, is that they did not provide an explanation of the mechanism whereby the informal sector might affect this ratio. Another major shortcoming was that it did not consider whether the coefficient might change over time, or whether the relationship between unemployment and output might change over the business cycle. We do not yet know the mechanism whereby the informal sector affects the workings of labour markets in both developed and developing economies, but especially the latter, which are the focus of this study. Thus, it is important to analyse the relationship between open unemployment, informal employment and the relationship of both with output fluctuations. We expect that this analysis will help towards an understanding of labour market dynamics in the least developed countries, including their unemployment performance.

It is well known that a salient feature of labour markets in least developed countries is the existence of a large informal sector. According to the International Labour Organization (ILO), more than half of all non-agricultural employment in developing countries is in the informal sector. In Latin America, for example, ILO estimates that informal employment ranges from about 30.9\% of employed workers in Costa Rica to about $72.8 \%$ in Honduras and $73.6 \%$ in Guatemala. Some $53.8 \%$ of non-agricultural employment in Mexico is informal.

ILO associates poor employment conditions and increasing poverty with informal employment. ${ }^{5}$ Informality has also been associated with other characteristics that developing economies exhibit: high tax evasion, limited coverage of social security institutions and a reduced ability to manage the economy (Vuletin, 2008).

We argue not only that informal employment lowers the sensitivity of unemployment to output changes but also that it can help us understand the dynamics of the labour market in least developed countries. In this paper, we propose an empirical model in which the transition from one regime to the

2 Or the impact of output growth on unemployment changes.

3 For a brief overview of some of these studies, see Silvapulle, Moosa and Silvapulle (2004) and Islas and Cortez (2013), among others.

4 The others are the mean unemployment rate, per capita GDP, the GDP share of the service sector and skill mismatches (Ball and others, 2016).

5 See [online] http://www.ilo.org/global/topics/employment-promotion/informal-economy/lang--en/index.htm. 
other depends on the change in informal employment. Following recent contributions on the non-linear Okun's coefficient, we test three models: a linear model, a non-linear fixed transition probabilities (FTP) model and a time-varying transition probabilities (TVTP) model.

Different theoretical models analyse the macroeconomic effects of the informal sector on developing economies. Agénor and Azenman (1999), for example, conclude within a general equilibrium framework that there is no close relationship between changes in output and unemployment and that a negative macroeconomic shock induces workers employed in the formal sector to move to the informal sector, with little effect on the aggregate unemployment rate. Other studies include those of Bhattacharya (2007), who analyses the relationship between the informal sector and income distribution in least developed countries, and Goldberg and Pavcnick (2003), who study the relationship between trade liberalization and informality. The main contribution of the present study is not claimed to be a theoretical one, the aim being rather to provide a plausible explanation of labour market dynamics when there is a large informal sector.

One of the largest Latin American economies, with a big non-agricultural informal sector, is Mexico. It also represents a unique case study because for three decades or so it has displayed one of the region's lowest unemployment rates and yet its growth performance has been rather disappointing. For these reasons, we picked Mexico for our study.

The paper is organized into a further six sections. Section II discusses recent studies of labour mobility between the formal and informal sectors in some Latin American countries. Section III briefly reviews some works on Okun's law. Section IV then considers recent estimations of Okun's coefficient for Mexico and describes the performance of the informal sector in the period of analysis. Low growth is compatible with low unemployment when there is a large informal sector. Section V describes the econometric models used to estimate the relationship between the cyclical components of output and unemployment. We propose three models and test whether the relationship is non-linear. Section $\mathrm{V}$ also describes the data used in the analysis. The empirical analysis is carried out in section VI, while section VII presents some concluding remarks.

\section{The informal sector and labour mobility in Latin America}

A key issue in the literature is the definition of informality. This has changed over the years. Originally, the term was used to describe a situation in which poor workers were employed in small production units because of a lack of better employment opportunities. The concept was later modified to include all workers not covered by labour legislation or social security (Tokman, 2011). Nowadays, the concept is somewhat more complex, as it includes a wide range of labour market activities which can be broadly grouped into two clusters. On the one hand, there are survival activities (casual jobs, temporary jobs, unpaid jobs, subsistence agriculture, multiple job holding). On the other, there are rational choice activities carried out in order to evade taxes, labour regulations and other government or institutional regulations. This includes non-registration of companies. ${ }^{6}$

Agreement on the definition of informality, however, has not led to consensus about how to measure it. Some researchers have taken workers employed in small production units not registered with regulatory institutions as a proxy for informal firms, while others have preferred to take workers without social benefits (e.g. health insurance and paid vacations) as the standard. A third group of researchers have combined both types of definitions. For example, Maloney's (1998) study of Mexico's labour

\footnotetext{
6 See World Bank Group [online] http://Inweb90.worldbank.org/eca/eca.nsf/1f3aa35cab9dea4f85256a77004e4ef4/2e4ede 543787a0c085256a940073f4e4?OpenDocument.
} 
market defines three types of informal workers: (i) the self-employed, i.e. owners of informal firms with or without additional employees; (ii) informal wage earners, who are people employed in informal firms; (iii) contract workers, i.e., those who do not receive a regular wage or salary but are paid a percentage, on a piecework basis, by commission or under a fixed-term contract and are often connected to larger firms. Gong, Van Soest and Villagomez (2004) take workers employed in small production units (less than five workers), while Calderon's (2000) study of Mexico's labour market treats as informal those workers who are not registered with social security institutions. Bosch and Maloney (2010) include both workers in small firms and those left uncovered by labour legislation. Galli and Kucera (2003) use a slightly different definition: in addition to those employed in small firms, they include self-employed and domestic workers.

There are two important questions researchers have addressed recently when discussing developing and developed economies' labour markets. The first is whether these markets can be characterized as segmented or not, and the second is the extent to which they are flexible in adjusting to output shocks. Maloney (1998), for instance, provides some evidence against the segmented labour market hypothesis in the case of Mexico by estimating the transition probabilities between the formal and informal sectors. In a longitudinal analysis of three cohorts of workers, ${ }^{7}$ he finds a significant probability of transition from the different types of informality to formal employment and vice versa. He estimates that the probabilities of transition from informal wage work, contract work and self-employment to formal wage work is about $42 \%$, whereas the probabilities of transition from formal wage work to these different types of informal work are $6 \%, 4 \%$ and $5 \%$, respectively; i.e., the flow runs in both directions, albeit with a much greater movement from informal to formal employment than from formal to informal. 8

Galli and Kucera (2003), on the other hand, argue from the buffer hypothesis that informal employment is countercyclical, i.e., a negative output shock can be expected to induce an expansion of the informal sector. However, the different types of informal employment cannot all be expected to respond in the same way to business cycles. For example, informality driven by a survival strategy is likely to be countercyclical and voluntary self-employment procyclical. Similarly, informal employment will be procyclical if firms decide to increase the amount of subcontracting during expansions but countercyclical if they decide to reduce this type of employment at those times.

Bosch and Maloney (2010), for example, find that the patterns in the Argentine and Brazilian labour markets are similar to that in the Mexican labour market. Indeed, they identify other similarities between these labour markets. First, both unemployment and informality are countercyclical, i.e., both increase during recessions and decline during expansions. Second, the transitions from informality to formality and vice versa are procyclical, largely because of the scale of transitions from formal employment to self-employment. In a study of El Salvador's labour market, Funkhouser (1997) estimated the transition in accordance with gender characteristics. He found that there was a fair amount of mobility between the formal and informal sectors. Of male workers originally in informal employment, $7.3 \%$ moved into formal employment, while the transition from formal to informal employment was about $4.7 \%$. The percentages of female workers were lower, at $2.1 \%$ and 3.3\%, respectively.

For the Mexican case, Rodríguez-Oreggia (2007) estimates the probability of transition from informal to formal employment and vice versa for different time periods. He finds that this transition probability is higher for the former than for the transition from formal to informal employment. Alcaraz, Chiquiar and Salcedo (2015) use a self-selection model to estimate relative prevalence among voluntary

\footnotetext{
7 Three cohorts of workers were taken from the National Urban Employment Survey (ENEU) in the period from the third quarter of 1990 to the second quarter of 1992. The cohorts are: third quarter of 1990 to third quarter of 1991, first quarter of 1991 to first quarter of 1992 and second quarter of 1991 to second quarter of 1992.

8 The analysis covers male workers aged 16 to 65 with secondary education or less in 16 metropolitan areas. Two definitions of informal employment are used: unprotected workers and people working in microenterprises.
} 
and involuntary workers. They find that between $10 \%$ and $20 \%$ of informal workers would prefer a formal job, but they also find that entry barriers to formal employment are statistically significant. They confirm the existence of segmentation, with both formal and informal employment being somewhat integrated.

Not long ago, Mexico's labour market was classified as a very rigid one, with Heckman and Pagés-Serra (2000) and Gil, Montenegro and Dömeland (2001), among others, arguing that it was heavily regulated by laws that impeded employment creation. The rigidity of federal labour law made it costly and difficult for firms to lay off workers during recessions, while they would hesitate to hire new workers during expansions because of the high costs involved, mainly as a result of the requirement to provide social benefits such as health insurance, housing loans, paid vacations and the like. This type of market rigidity explained why output changes could result in only small unemployment changes, as González Anaya (2002) argued.

Recent studies, however, have noted the significant changes that Mexico's labour market has undergone, particularly in the form of significant growth in informal employment. The existence of a large informal market with significant labour mobility between formal and informal employment suggests that Mexico's labour market can be characterized as a hybrid market, wherein firms in the formal sector are increasingly using different employment schemes in an effort to reduce their labour costs (Contreras, 2000; De la Garza, n/d).

Furthermore, it might be expected from the scale of informal employment and the barriers to entry to formal employment that, for instance, expectations of falling output would induce firms to reduce their recruitment plans. ${ }^{9}$ This, in turn, would induce workers to either take an informal job or become unemployed. By the same token, rising output would induce firms to increase hiring under the flexible schemes available to them. Informal employment would decline and so would unemployment. It should be pointed out that unemployment changes would be smaller in either case than if the informal sector did not exist. This can be seen from the significant probability of transition from formal to informal employment, which prevents a much larger transition from formal employment to unemployment.

\section{A few notes on Okun's coefficient}

Since Okun's ground-breaking paper, the literature on the relationship between output growth and unemployment change has grown considerably. This literature provides support for the empirical validity of the trade-off between these two variables, although there is vast evidence that the magnitude of Okun's coefficient varies significantly within a given country (over time) and across countries (see, for instance, Silvapulle, Moosa and Silvapulle, 2004; Lee, 2000; and Harris and Silverstone, 2001). These studies are a radical departure from earlier ones which assumed that the coefficient was stable and reliable over time (Gordon, 1984).

The non-constancy of the coefficient has been attributed to a number of factors. From an accounting perspective, several authors have noted that its size depends on the evolution of variables such as technology, working hours, the capital utilization rate (Prachowny, 1993) and factor substitution (Courtney, 1991). Other studies have noted that the coefficient is also sensitive to model specification, which includes the form of the model (static versus dynamic), and to the detrending method used to remove non-stationarity: the first difference model versus the gap model (Crespo, 2003). ${ }^{10}$

9 In some cases, firms would reduce the number of full-time workers and increase the number of part-time jobs under the subcontracting system.

10 In the first difference model, output and unemployment are expressed in first difference (growth rates), while in the gap model they are considered as deviations from the long-term trend. Within the latter, a new question emerges: which filter to use. For example, in a comparative analysis across developed economies, Lee (2000) evaluated the stability and robustness of the law given that many European countries' labour market institutions had undergone changes. 
One of the earliest investigations into a non-linear relationship between output growth and unemployment changes was Courtney (1991). Following a long tradition of research on United States business cycles, Courtney found that Okun's coefficient was dependent on the state of the cycle. In particular, he found that the effect of output growth on unemployment change was stronger in contractions than in expansions. He further argued that unobserved labour hoarding might be an important determinant of state dependence in Okun's law and specifically contended that it was the substitution between employees' hours and effort that explained the asymmetric behaviour of employment over the business cycle.

A priori, we cannot say whether it is in expansions or recessions that output change has the greatest impact on unemployment change. There are two contending explanations. On the one hand, there is the view that when the economy begins to contract, firms respond very quickly by laying off workers. As the recession ends, fearing that recovery may not last long, they adjust productivity, the number of hours worked or both rather than the number of workers (Jardin and Stephan, 2011). This asymmetric behaviour would provide an explanation for output growth having a stronger effect on unemployment during recessions than during expansions. The contrasting view is that firms are unwilling to lay off workers during recessions because of the high costs involved (due to labour laws) and because their investment in workers' training would be lost. It is further argued that these firms should hire more workers during recoveries because there are few institutional constraints. From this perspective, output growth would be expected to have a greater impact on unemployment during expansions than during recessions.

There were several additional conclusions in this study. First, even though the results were qualitatively similar, the authors found significant quantitative differences across countries. Second, the gap model yielded stronger evidence that the coefficient did not remain constant over time across countries than the first difference model. Third, a structural break was found somewhere in the early 1970s in most European countries, the exceptions being Austria and Canada. Fourth, the coefficient was much lower for most European countries than for the United States.

Harris and Silverstone (2001) further extended the analysis of asymmetry for key countries of the Organization for Economic Cooperation and Development (OECD) by estimating the long-run and short-run coefficients. ${ }^{11}$ They found that the long-run coefficient lay between -0.39 and -0.5 , with the United Kingdom and Japan being outliers. In the short run, they found evidence that unemployment adjusted asymmetrically to output growth; specifically, that it adjusted in the expected manner during the downturn of the business cycle. They did not find reliable evidence for the response of output to changes in unemployment. In terms of policy implications, a non-linear Okun's law would suggest that an asymmetric policy response is required to reduce output fluctuations. In some cases, unemployment changes would suffice, whereas in others price adjustments would be required to achieve equilibrium.

Crespo (2003) and Silvapulle, Moosa and Silvapulle (2004), among others, have found that regardless of the filtering technique used, non-linear models explain the relationship between the cyclical components of output and unemployment better than linear models. Both these studies also find that the impact of output on unemployment is stronger during recessions than during expansions. ${ }^{12}$

The works reviewed so far use a deterministic approach to estimate the asymmetric Okun's coefficient in the sense that they treat the switch from one regime to another as an exogenous and deterministic event. Since the early 2000s, however, this view has been overtaken by a new approach

\footnotetext{
${ }^{11}$ The sample included Australia, Canada, Germany, Japan, New Zealand, the United Kingdom and the United States. They used the Engel-Granger methodology for cointegrated series, wherein the error correction term is adjusted to incorporate asymmetry. Their procedure involved estimating the threshold points that minimized the sum squared residuals through a grid search.

${ }^{12}$ Crespo (2003), for example, applies both the Hodrick-Prescott (HP) filter to each series individually and the bivariate structural time series model proposed by Harvey (1989). Silvapulle, Moosa and Silvapulle (2004) also use Harvey's bivariate methodology to detrend the series.
} 
that not only measures this switch by the probability of transition between the two states but posits that the change in regime is triggered by the size of the output gap. Moreover, the size of output gap required to induce the change in regime is estimated within the model.

\section{Informality and Okun's coefficient: the case of Mexico}

Not many papers have estimated Okun's coefficient for Mexico, and there is no consensus about its size. Chavarín (2001), for example, estimated that the coefficient was close to Okun's original calculations for the United States economy. ${ }^{13}$ González Anaya (2002) and Islas and Cortez (2013), ${ }^{14}$ however, find much smaller coefficients. These smaller coefficients are puzzling, since the increasing flexibility of Mexico's labour market since the mid-1990s would suggest that the effect of output growth on unemployment should have been much larger.

It is not clear that greater labour market flexibility would necessarily be reflected in larger fluctuations in employment, however. There are two answers to the question about the likely effects of output fluctuations on unemployment fluctuations when labour markets are more flexible. If this flexibility involves the terms of employment, i.e., firms can hire and fire workers according to their production needs, then the answer is that output fluctuations should indeed have a greater effect on unemployment fluctuations. However, if flexibility involves the ability to recruit workers under flexible employment schemes, then output fluctuations should have a rather small impact on unemployment fluctuations, but should prompt greater mobility of workers between the different types of employment. The unemployment rate would still be affected by output fluctuations, but to a lesser extent. ${ }^{15}$

This is where the informal sector comes in. It has been recognized that several of these types of jobs are actually informal jobs in the sense that they do not provide the basic social benefits that formal employment does. If employment in informal firms is additionally taken into account, then cyclical output should have an even smaller effect on cyclical unemployment. The evidence presented in section II clearly brought out the significant scale of transition from formal to informal employment (and vice versa). Hence, when the informal sector is large, the effect of cyclical output on cyclical employment should be rather small, a finding already noted by Agénor and Aizenman (1999) and Dell'Anno and Solomon (2008).

As noted in section II, there are several definitions of informality. In what follows, informal employment (or employment in the informal sector) is defined as encompassing people working in informal firms. Informal firms are defined as those that are not registered with any government agency. Given that the main purpose of this study is to analyse how informal employment can affect the relationship between the short-term components of unemployment and output, no distinction is made between the different types of informal employment.

Table 1 presents a cross-correlation between gross domestic product (GDP) growth rates, informal employment and unemployment.

\footnotetext{
${ }^{13}$ Chavarín (2001) estimated that a 1 percentage point change in unemployment would induce a change of around 2.7 percentage points in output. Conversely, a 1 percentage point change in output was associated with a change of 0.3 percentage points in unemployment in the opposite direction.

${ }^{14}$ Islas and Cortez (2013) estimate that a 1 percentage point change in output is associated with a -0.5 percentage point change in unemployment, while a 1 percentage point change in unemployment is associated with a -1.66 percentage point change in output.

${ }^{15}$ Gong, Van Soest and Villagomez (2000) found evidence that the probability of transition from both formal and informal employment to unemployment was greater during recessions than in periods of expansion.
} 
Table 1

Mexico: cross-correlation of GDP growth, informal employment and unemployment, first quarter of 1993 to second quarter of 2015

\begin{tabular}{|c|c|c|c|c|c|c|c|c|c|c|c|c|c|}
\hline & -6 & -5 & -4 & -3 & -2 & -1 & 0 & 1 & 2 & 3 & 4 & 5 & 6 \\
\hline$(G D P, i n f)$ & 0.009 & 0.211 & 0.149 & 0.012 & 0.104 & -0.059 & -0.102 & -0.008 & -0.197 & -0.097 & 0.124 & 0.028 & 0.014 \\
\hline$(G D P, \mu)$ & 0.053 & 0.032 & -0.069 & 0.093 & 0.004 & -0.143 & -0.375 & -0.307 & -0.082 & 0.058 & -0.070 & 0.054 & 0.037 \\
\hline$(\mu, \inf )$ & -0.050 & 0.048 & -0.019 & -0.121 & 0.037 & -0.050 & -0.315 & 0.182 & 0.022 & 0.033 & 0.077 & 0.017 & 0.074 \\
\hline
\end{tabular}

Source: Prepared by the authors, on the basis of data from the National Urban Employment Survey (ENEU) and the National Survey of Occupation and Employment (ENOE).

Table 1 shows the cross-correlations between growth in GDP and informal employment (first row), growth in GDP and unemployment (second row) and growth in unemployment and informal employment (third row). The results indicate that informal employment leads the cycle and is procyclical. When lagged informal employment is taken, its relationship with output is found to turn negative, meaning that it becomes countercyclical. Unemployment is, as expected, countercyclical and contemporaneous. The results also indicate that the growth rates of unemployment and informal unemployment are negatively related and contemporaneous.

Traditional measures of Okun's coefficient for the relationship between unemployment and output show these as contemporaneous. The results presented in table 1 seem to confirm this, but they also suggest that informal employment starts to signal a recovery or slowdown a few quarters before this shows up in output. They also suggest that the relationship does not remain constant over time, as can be seen from the sign and size of the correlation coefficient at lag 5 .

This last point is in line with Oliveira's (2002) conclusion that Mexico's business cycle is asymmetrical, with recessions being acuter and shorter than expansions. We thus argue that the relationship between the growth rates of unemployment and output depends on the state the economy is in, and specifically that this relationship is stronger during recessions than during expansions.

Now, in order to assess the impact of informal employment on the probability of transition from one regime to the other, let us define the regime the economy is in by the unemployment rate. The economy will be considered to be in the expansionary state whenever current unemployment is below its long-run trend and in the recessionary state whenever it is above this.

The following section provides details of the probability of transition from one regime to the other, and of the estimation technique.

\section{Methodology}

\section{Empirical models}

We estimate three models to measure the trade-off between cyclical output and cyclical unemployment. Model 1 assumes a linear relationship, model 2 is a Markov switching regime model with fixed transition probability (FTP) and model 3 relaxes the fixed transition probability assumption and is a-time varying transition probability model. As Filardo (1994) and Diebold and Rudebusch (1999) explain, the Markov switching model with time-varying transition probability (TVTP) is more flexible than the FTP. It recognizes systematic changes in transition probabilities before and after turning points, captures more complex temporal persistence and allows expected duration to vary over time. In this context, economic fundamentals and policy shocks can influence regime transition probabilities. 
First, we consider the traditional linear regression-based model proposed by Moosa (1997) and label it model 1. It is as follows:

$$
u_{t}^{c}=\alpha_{0}+\beta y_{t}^{c}+\sum_{i=1}^{p} \alpha_{j} u_{t-j}^{c}+\varepsilon_{t}, \varepsilon_{t} \sim N I D\left(0, \sigma^{2}\right)
$$

where $u_{t}^{c}$ denotes cyclical unemployment and $y_{t}^{c}$ cyclical output. Lagged cyclical unemployment has to be included to remove serial correlation. Okun's coefficient is measured by the estimated value of $\beta$, the impact coefficient, such that $\beta<0$.

In addition to the linear regression-based model, we consider the Markov switching FTP model to characterize the regime-dependent specification of Okun's law, which allows for an asymmetric effect of cyclical output on cyclical unemployment. The general idea behind this class of regime-switching models is that the regression parameters depend upon a stochastic, unobservable regime variable $s_{t} \in\{1,2\}$. The stochastic process for generating the unobservable regime is an ergodic Markov chain defined by the transition probability $p_{i j}=\operatorname{Pr}\left(s_{t+1}=j \mid s_{t}=i\right)$, where $i, j=1$ or 2 . The transition probability $p_{i j}$ gives the probability that state $i$ will be followed by state $j$. The transition matrix is

$$
P=\left[\begin{array}{ll}
p_{11} & p_{21} \\
p_{12} & p_{22}
\end{array}\right]
$$

where $p_{11}$ is the probability of remaining in the expansionary regime, defined as the outcome where $p_{22}$ the unemployment rate is below its trend, while $p_{22}$ is the probability of remaining in the recessionary regime, defined as the situation where the unemployment rate is above trend.

The time regime-dependent specification of Okun's law which allows for an asymmetric effect, model 2 , is as follows:

$$
u_{t}^{c}=\alpha_{0 s_{t}}+\beta_{s_{t}} y_{t}^{c}+\sum_{i=1}^{p} \alpha_{j-1 s_{t}} u_{t-j}^{c}+\varepsilon_{t}, \varepsilon_{t} \sim N I D\left(0, \sigma_{s_{t}}^{2}\right)
$$

where $\alpha_{j s_{t}}=\alpha_{j 1}, \beta_{s_{t}}=\beta_{1}, \sigma_{s_{t}}^{2}=\sigma_{1}^{2}$ if $s_{t}=1$, for $j=0,1, \ldots, p$, while $\alpha_{j s t}=\alpha_{j 2}, \beta_{s t}=\beta_{2}, \sigma_{s_{t}}^{2}=\sigma_{2}^{2}$ if $s_{t}=2$, for $j=0,1, \ldots, p$.

Model 2 features two coefficients, $\beta_{1}$ and $\beta_{2}$. A priori, we expect that $\beta_{1}, \beta_{2}<0$, with cyclical unemployment responding negatively to cyclical output in either expansionary or recessionary regimes.

Finally, we consider model 3, which allows for the possibility of time-varying transition probabilities. For information variables in $z_{t}$, we choose the informal employment rate, since we assume that it has been the main cause of changes in the unemployment rate (see section IV). This is a departure from other studies, which have used the output gap or capacity utilization as the leading variable in the time-varying transition probability. Therefore, model 3 considers the following time-varying transition probabilities:

$$
\begin{aligned}
& P\left[s_{t}=1 \mid s_{t-1}=1, \underline{z}_{t-1} ; \underline{\delta}_{1}\right]=p\left(\underline{z}_{t-1}\right)=\Phi\left(\underline{z}_{t-1}^{\prime} \underline{\delta}_{1}\right) \\
& P\left[s_{t}=2 \mid s_{t-1}=2, \underline{z}_{t-1} ; \underline{\delta}_{2}\right]=q\left(\underline{z}_{t-1}\right)=\Phi\left(\underline{z}_{t-1}^{\prime} \underline{\delta}_{2}\right)
\end{aligned}
$$

where $\Phi($.$) refers to the cumulative density function of the standard normal distribution evolving as a function$ of $\underline{z}_{t-1}^{\prime} \underline{\delta}_{i}, i=1,2$, where the $(m x 1)$ conditioning vector $\underline{z}_{t-1}^{\prime}=\left(1, \Delta e_{\text {inf }}, \Delta e_{t-1}, f_{t-2}, \ldots, \Delta e_{\text {inf }} t_{t-m-1}\right)$, $\underline{\delta}_{i}{ }^{\prime}=\left(\delta_{i 0}, \delta_{i 1}, \ldots, \delta_{i, m-1}\right), i=1,2$, and $\Delta e_{i n f}{ }_{t}$ denotes the first difference of the informal employment rate. The two-point stochastic process on $s_{t}$ can be summarized by the transition matrix 


$$
P\left[s_{t}=1 \mid s_{t-1}=1, \underline{z}_{t-1} ; \underline{\delta}_{i}\right]=\left[\begin{array}{cc}
p\left(\underline{z}_{t-1}\right) & 1-p\left(\underline{z}_{t-1}\right) \\
1-q\left(\underline{z}_{t-1}\right) & q\left(\underline{z}_{t-1}\right)
\end{array}\right]
$$

where the history of the state of informal unemployment is in $\underline{z}_{t-1}$.

In the time-varying transition probability Markov switching model, transition probabilities are allowed to vary with the state of informal employment (upswing and downswing). The probabilities in model 3 reflect the duration of the Okun relationship expressed as a regime-dependent specification. For the model specification test, we follow Engel and Hamilton (1990), proving the following hypothesis:

$$
H_{0}^{s s}: \alpha_{j 1}=\alpha_{j 2}, \beta_{1}=\beta_{2}, \sigma_{1}^{2} \neq \sigma_{2}^{2} ; j=0,1,2, \ldots, p
$$

If we cannot reject $H_{0}^{S S}$, the implication is that the true data-generating process derives from a single state as opposed to two states. The test statistic for the $H_{0}^{S S}$ hypothesis is the Wald statistic, and it has the $\chi_{(v)}^{2}$. If we let $\sigma_{1}^{2}=\sigma_{2}^{2}$, the test of $H_{0}^{S S}$ has the so-called "nuisance parameter problem", i.e., the parameters $p_{11}$ and $p_{22}$ are unidentified.

To estimate models 1 to 3 , we need time series for the unobserved components $u_{t}^{c}$ and $y_{t}^{c}$. The cyclical components can be extracted by means of different methodologies, e.g., by considering a single or multiple time series setting. Here we concentrate on a bivariate time series approach that assumes the observed time series vector to be composed of an unobserved vector of trends plus a vector of cycles and takes into account the correlation between output and unemployment cycles. Laxton and Tetlow (1992) provided a historical overview of estimation procedures for potential output and found that two approaches had basically been employed since the 1980s: (i) structural approaches relying on a structural economic model, as in Ford and Rose (1989) and Adams and Coe (1990); (ii) stochastic approaches such as the one underlying the filter developed by Hodrick and Prescott (1981 and 1997). Laxton and Tetlow (1992) combined these approaches and proposed a semi-structural technique which is known as the Hodrick-Prescott multivariate filter (HPMV) (see, for example, Boone, 2000 and Chagny and Lemoine, 2002). However, the HPMV is not a true multivariate filter, but rather a multiple time series filter. The difference is akin to that between multiple regression, where there is only one dependent variable to be explained by several independent ones, and multivariate regression, where several dependent variables are to be explained simultaneously by one or more independent variables.

We use a different semi-structural technique based on a true multiple time series filtering method that was proposed by Guerrero, Islas and Ramírez (2017) and is known as the bivariate Hodrick-Prescott (BHP) filter. This new method can be used to extract a pair of trends that might share similar dynamic behaviours. One advantage of this method is that it employs only the first two sample moments of the variables involved. A second significant advantage is that it provides a way of deciding the value of the smoothing parameter that produces the desired percentage of smoothness for the trends. A third advantage is that it takes simultaneity in the estimation into account, correcting for likely biases. Further details of the methodology are available in a technical appendix available from the authors upon request. 


\section{The data}

The key variables are output, unemployment and informal employment. Mexican GDP figures are those calculated by the National Institute of Statistics and Geography (INEGI) on a quarterly basis in real pesos, with 2008 as the base year. The unemployment series is the alternative unemployment rate estimated following the United States Bureau of Labor Statistics methodology. ${ }^{16}$ There are two sources for the labour series (unemployment and informal employment): the National Survey of Urban Employment (ENEU) and the National Survey of Occupation and Employment (ENOE).

Both the unemployment rate and the informal sector rate are estimated for the 11 largest cities in Mexico. ${ }^{17}$ We selected those cities because they were the only ones that were in both surveys (ENEU and ENOE) and could thus be made to yield a time series. We considered workers aged between 16 and 75 . All data are quarterly and seasonally adjusted, covering the period from the first quarter of 1993 to the second quarter of 2015. Informal sector employees are defined as workers employed at unregistered firms. ${ }^{18}$

Figure 1 describes the behaviour of the jointly estimated cyclical components of output and unemployment, which were extracted using the methodology proposed by Guerrero, Islas and Ramirez (2017). This chart shows that the behaviour of the cyclical components is consistent with the economic theory of Okun's law, implying that cyclical unemployment is negative only if cyclical output is positive and vice versa.

Figure 1

Mexico: estimates of cyclical output and unemployment, bivariate Hodrick-Prescott filter with 90\% smoothness, first quarter of 1990-first quarter of 2015

A. Cyclical component of unemployment

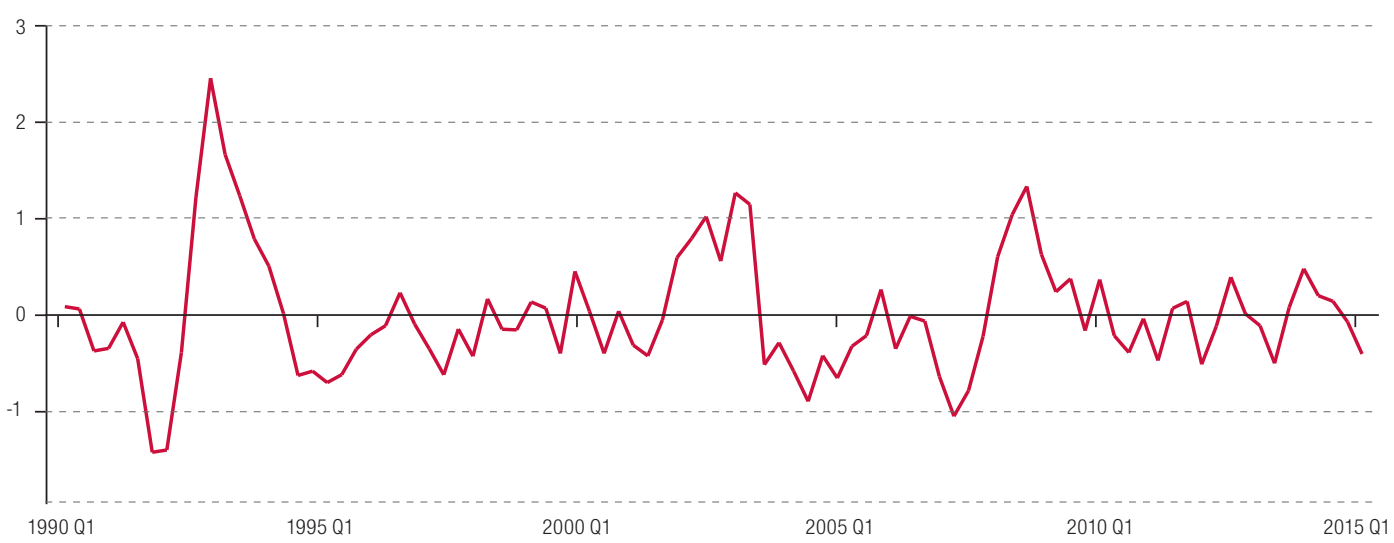

\footnotetext{
${ }^{16}$ See Fleck and Sorrentino (1994) and Martin (2000) for a discussion of the main differences between the methodology used by Mexico's INEGI to estimate unemployment and that of the Bureau of Labor Statistics. Traditionally, the INEGI methodology has grossly underestimated the unemployment rate, and although it has now been adjusted in some respects, there are still elements that flatter the Mexican unemployment rate relative to that of the United States economy.

17 The cities considered in the analysis are Chihuahua, Guadalajara, León, Mérida, Mexico City, Monterrey, Puebla, San Luis Potosí, Tampico, Tijuana and Veracruz.

18 It should be noted that this definition of informality is different from the definition of informal employment, which refers to employment not covered by social benefits, some of which may be in formal firms.
} 
Figure 1 (concluded)

B. Cyclical component of output

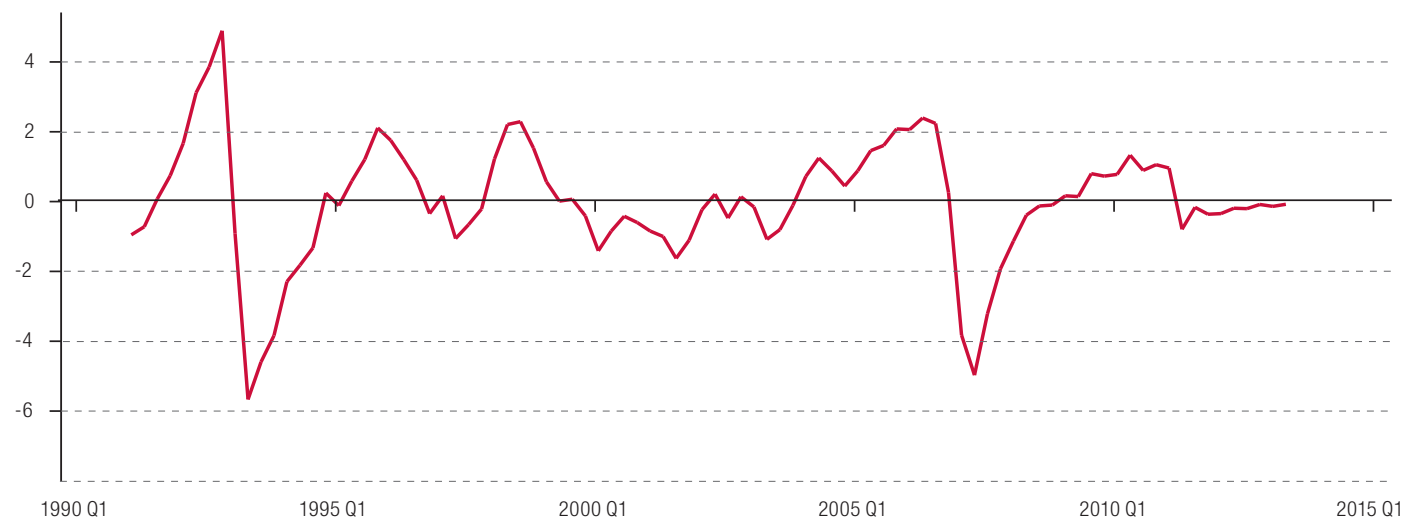

Source: Prepared by the authors.

\section{Empirical results}

After obtaining the cyclical components $u_{t}^{c}$ and $y_{t}^{c}$, we proceeded to estimate both linear and non-linear models. Table 2 presents the results for the three models.

The lag length of the autoregressive component of cyclical unemployment, $p$, was chosen as the one to minimize Akaike's information criterion. Starting with a maximum of six lags, the inclusion of one lagged value of $u^{c}$ for model 1 , five for model 2 and six for model 3 (together with one lag for $\Delta e_{i n f_{t}}$ in the TVTP model) was found to be accepted.

Table 2

Estimated results from models 1, 2 and 3

\begin{tabular}{|c|c|c|c|c|c|}
\hline \multicolumn{2}{|c|}{ Model 1} & \multicolumn{2}{|c|}{ Model 2} & \multicolumn{2}{|c|}{ Model 3} \\
\hline Parameter & Estimated & Parameter & Estimated & Parameter & Estimated \\
\hline$\alpha_{0}$ & $\begin{array}{l}-0.0010 \\
(0.0430) \\
\end{array}$ & $\alpha_{01}$ & $\begin{array}{l}-0.0374 \\
(0.0395)\end{array}$ & $\alpha_{01}$ & $\begin{array}{r}-0.0567^{\star \star} \\
(0.0288)\end{array}$ \\
\hline$\beta_{1}$ & $\begin{array}{r}-0.1806^{\star \star \star} \\
(0.0314)\end{array}$ & $\beta_{1}$ & $\begin{array}{r}-0.1207^{\star \star *} \\
(0.0377) \\
\end{array}$ & $\beta_{1}$ & $\begin{array}{r}-0.1092^{\star \star *} \\
(0.0295) \\
\end{array}$ \\
\hline \multirow[t]{11}{*}{$\alpha_{1}$} & $\begin{array}{r}0.4404^{\star \star \star} \\
(0.0623)\end{array}$ & $\alpha_{11}$ & $\begin{array}{r}0.4059^{\star * *} \\
(0.0924)\end{array}$ & $\alpha_{11}$ & $\begin{array}{r}0.3875^{\star \star \star} \\
(0.0220)\end{array}$ \\
\hline & & $\alpha_{21}$ & $\begin{array}{l}0.0335 \\
(0.186)\end{array}$ & $\alpha_{21}$ & $\begin{array}{l}-0.0601 \\
(0.0106)\end{array}$ \\
\hline & & $\alpha_{31}$ & $\begin{array}{r}0.0894 \\
(0.1025) \\
\end{array}$ & $\alpha_{31}$ & $\begin{array}{r}0.2070^{\star *} \\
(0.0971) \\
\end{array}$ \\
\hline & & $\alpha_{41}$ & $\begin{array}{r}-0.2414^{\star *} \\
(0.0876)\end{array}$ & $\alpha_{41}$ & $\begin{array}{r}-0.3751^{\text {*** }} \\
(0.1009)\end{array}$ \\
\hline & & $\alpha_{51}$ & $\begin{array}{r}0.0002 \\
(0.0832)\end{array}$ & $\alpha_{51}$ & $\begin{array}{r}0.1523 \\
(0.1119) \\
\end{array}$ \\
\hline & & $\alpha_{02}$ & $\begin{array}{c}0.2259^{\star \star} \\
(0.0923)\end{array}$ & $\alpha_{61}$ & $\begin{array}{r}-0.1543^{*} \\
(0.0828)\end{array}$ \\
\hline & & $\beta_{2}$ & $\begin{array}{r}-0.3117^{\star \star \star} \\
(0.0152)\end{array}$ & $\alpha_{20}$ & $\begin{array}{l}0.2307^{*} \\
(0.0932)\end{array}$ \\
\hline & & $\alpha_{12}$ & $\begin{array}{r}0.7537^{* * *} \\
(0.1391)\end{array}$ & $\beta_{2}$ & $\begin{array}{r}-0.2606^{\star * *} \\
(0.0369)\end{array}$ \\
\hline & & $\alpha_{22}$ & $\begin{array}{r}-0.4835^{\star} \\
(0.2534)\end{array}$ & $\alpha_{21}$ & $\begin{array}{r}0.5920^{\text {*** }} \\
(0.1572)\end{array}$ \\
\hline & & $\alpha_{32}$ & $\begin{array}{r}1.2359^{\star \star *} \\
(0.2754)\end{array}$ & $\alpha_{22}$ & $\begin{array}{r}0.0803 \\
(0.2241)\end{array}$ \\
\hline & & $\alpha_{42}$ & $\begin{array}{r}-0.7215^{\star \star} \\
(0.2417)\end{array}$ & $\alpha_{32}$ & $\begin{array}{r}0.0503 \\
(0.1992)\end{array}$ \\
\hline
\end{tabular}


Table 2 (concluded)

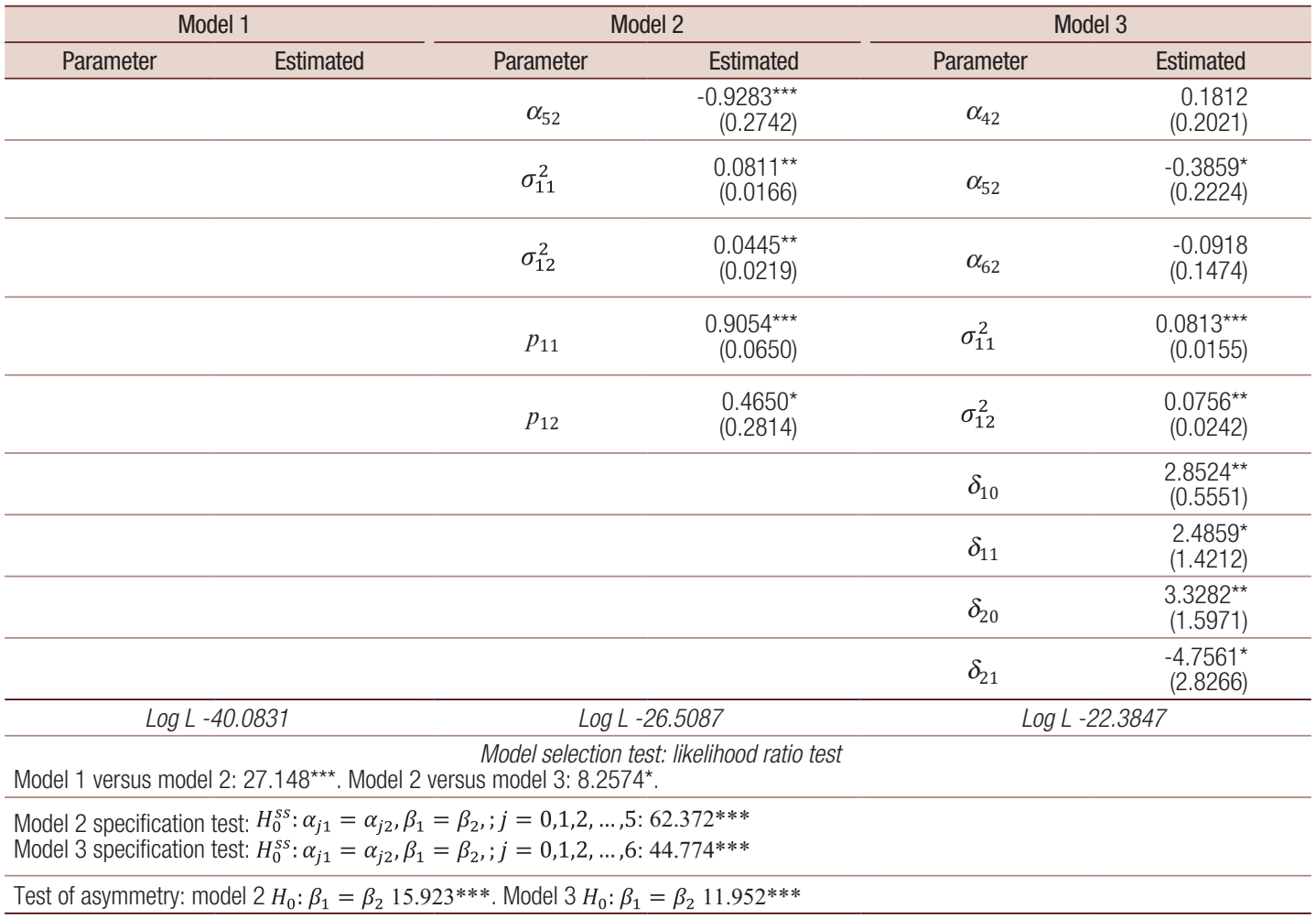

Source: Prepared by de authors.

Notes: The numbers in brackets are standard errors. ${ }^{\star \star \star}$, ${ }^{\star \star}$ and * denote significance at the $1 \%, 5 \%$ and $10 \%$ levels, respectively.

Given that three different models are considered in this paper, the likelihood ratio test was first used for model selection, the results being summarized in table 2 . The likelihood ratio statistic suggests that model 2 (the FTP regime-dependent specification of Okun's law) is preferable to model 1 (the linear specification of Okun's law). This yields evidence of non-linearity in Okun's law for Mexico. The results also indicate that the mean cyclical unemployment rate is lower in the expansionary regime than in the recessionary regime $(-0.0374<0.2259)$. As mentioned earlier, the expansionary and recessionary regimes are described as outcomes where unemployment is below and above trend, respectively. Across the two regimes, the two state-dependent Okun's coefficients $\left(\beta_{1}, \beta_{2}\right)$ are negative and significant at the $1 \%$ level. Further testing results in rejection of the null hypothesis $H_{0}: \beta_{1}=\beta_{2}$, a result that supports the existence of an asymmetric Okun's coefficient. Cyclical unemployment is more responsive to contemporaneous cyclical output when the former is in the recessionary regime. The results indicate that a decrease of $1 \%$ in cyclical output is accompanied by an increase of approximately $0.31 \%$ in unemployment if the system is in a recessionary regime, while an increase of $1 \%$ in cyclical output reduces unemployment by approximately $0.12 \%$ when the system is in an expansionary regime.

Furthermore, the probability $p_{11}$ of remaining in the expansionary regime at time $(t)$, given that the unemployment rate was in the same regime at time $(t-1)$, is 0.90 . The probability $p_{22}$ of being in the recessionary regime at time $(t)$, given that the unemployment rate was in the same regime at time $(t-1)$, is 0.53 , smaller than $p_{11}$. These probability values indicate that if the unemployment rate is in the expansionary regime, it is more likely to remain in this regime than to switch to a recessionary one. In addition, table 2 shows that the probability of switching from an expansionary to a recessionary regime is almost 0.095 , while the probability of switching from a recessionary to an expansionary regime is close to 0.47 , which indicates that changes from recessionary to expansionary regimes are more likely than changes from expansionary to recessionary ones. The expected duration of regime $j$ is defined 
as $1 /\left(1-p_{i j}\right)$. Going by this result, we found that the average length of an expansionary regime was two and a half years, whereas the expected duration of a recessionary regime was approximately half a year.

We now estimate the model in terms of transitional endogenous probabilities. Unlike other papers that use output changes, this one allows the informal employment rate to explain the evolution of such probabilities. As explained in section IV, we consider informal employment to be one of the main causes of changes in the unemployment rate.

The likelihood ratio test comparing the model of time-varying transition probabilities with the model of fixed probabilities rejects the null hypothesis of constant probabilities in favour of the TVTP model. On the basis of these tests, we conclude that the model with endogenous transition probabilities is the best one for explaining the relationship between the cyclical components of unemployment and output.

The TVTP estimations, also shown in table 2, validate the existence of two different states of the unemployment rate: an expansionary regime with negative mean cyclical unemployment $(0.0567)$ and a recessionary regime with positive mean cyclical unemployment (0.2307). In this case, average mean cyclical unemployment in expansionary, and recessionary regimes are similar to those found for the FTP case.

We observe that the sign of the explanatory variable of the transition probabilities accords with economic intuition. In fact, the probability of remaining in an expansionary regime, with below-trend unemployment, increases with a rise in the informal employment rate. On the other hand, if the unemployment rate is in a recessionary regime, with above-trend unemployment, a rise in the informal employment rate decreases the probability of remaining in this regime.

As in the FTP model, the two state-dependent Okun's coefficients $\left(\beta_{1}, \beta_{2}\right)$ are negative and significant at the $1 \%$ level across the two regimes. Further testing results in rejection of the null hypothesis $H_{0}: \beta_{1}=\beta_{2}$, a result that supports the existence of an asymmetric Okun's coefficient. Cyclical unemployment is more responsive to contemporaneous economic growth when in the recessionary regime. The results indicate that a decrease of $1 \%$ in cyclical output is accompanied by an increase of approximately $0.26 \%$ in unemployment if the unemployment rate is in the recessionary regime, while an increase of $1 \%$ in cyclical output decreases unemployment by approximately $0.10 \%$ if unemployment is in the expansionary regime. Our results indicate that when informal employment is allowed to explain the evolution of transition probabilities, Okun's coefficient estimates are smaller than the estimates yielded by the FTP model. This corroborates our claim that when there is a large informal sector, the effect of cyclical output on cyclical employment should be rather small.

Figure 2 shows the smoothed TVTP of being in a recessionary regime with above-trend unemployment at each date in the sample obtained from the model of endogenous probabilities. The time when the unemployment rate switched from one regime to the other is based on $P\left(s_{t}=\operatorname{res} \mid u_{1}^{c}, \ldots, u_{T}^{c} ; \widehat{\Theta}\right) \geq 0.5$ The switching between regimes is usually sudden, thorough and sporadic. The unemployment rate spends most of the time in an expansionary regime. Figure 2 indicates four changes from an expansionary to a recessionary regime during the sample period. The first occurred between the fourth quarter of 1994 and the third quarter of 1995, the period of the Mexican financial crisis of 1994. The second was between the second quarter of 2003 and the first quarter of 2005: the upward trend in the Mexican unemployment rate during this period could be related to the slowdown in Mexico at that time, with the economy stagnating in the second and third quarters of 2003, the second and third quarters of 2004 and the first quarter of 2005. The third was in the second quarter of 2008, when the global financial crisis started. The last switch from an expansionary to a recessionary regime occurred in the first quarter of 2013, and could be related to the performance of the Mexican economy. The economy grew by $1.1 \%$ in 2013, a large drop on the 3.9\% expansion of 2012, making this its weakest performance since 2009, when there was a deep recession. 
Figure 2

Smoothed probabilities of being in a recessionary regime, time-varying transition probabilities (TVTP) model

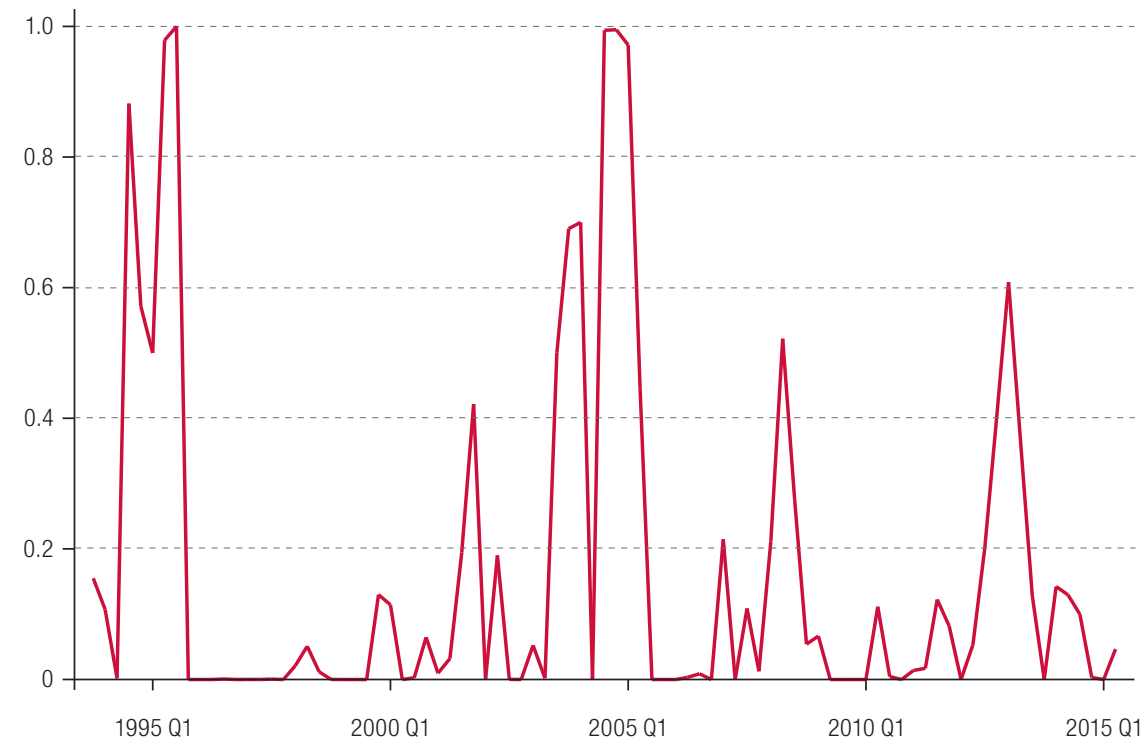

Source: Prepared by the authors.

\section{VII.Conclusions}

This paper evaluates the way a large informal sector influences the impact of output fluctuations on unemployment fluctuations. It also considers the possibility that this influence may change over the course of Mexico's business cycle. A non-linear specification of the relationship between cyclical unemployment and cyclical output was estimated for the Mexican economy. A Markov switching model with both fixed and time-varying transition probabilities was used to identify the presence of asymmetry across regimes. In the model of endogenous probabilities in particular, we allowed the probabilities to be affected by the rate of informal employment, which we consider to be the main cause of changes in the unemployment rate.

Our findings can be summarized as follows. First, we corroborate previous estimates that Okun's coefficient is rather low. We argue that this low coefficient is largely explained by the existence of a large informal sector and a high level of mobility between the formal and informal sectors. Second, we find evidence of a non-linear Okun's coefficient in Mexico. In particular, our results support the existence of regime-dependent Okun's parameters with a significantly higher absolute value for recessions than for expansions. This implies that cyclical unemployment is more responsive to changes in cyclical output when in the recessionary regime. Third, the hypothesis of fixed probabilities can be rejected in favour of time-varying transition probabilities, which means that a model with endogenous transition probabilities is the better one. Fourth, we propose that informal employment significantly affects the evolution of the unemployment rate. We find that the probability of remaining in an expansionary regime with below-trend unemployment increases with a rise in the informal employment rate, while if the unemployment rate is in a recessionary regime and is above trend, an increase in the informal employment rate reduces the probability of remaining in this regime. 


\section{Bibliography}

Adams, C. and D. T. Coe (1992), "A systems approach to estimating the natural rate of unemployment and potential output for the United States", The United States Economy: Performance and Issues, Y. Horiguchi (ed.), Washington, D.C., International Monetary Fund (IMF).

Agénor, P. R. and J. Aizenman (1999), "Macroeconomic adjustment with segmented labor markets", Journal of Development Economics, vol. 58, No. 2, Amsterdam, Elsevier.

Alcaraz, C., D. Chiquiar and A. Salcedo (2015), "Informality and segmentation in the Mexican labor market", Working Paper, No. 2015-25, Mexico City, Banco de México.

Ball, L. and others (2016), "Does one law fit all? Cross-country evidence on Okun's law", paper presented at the Global Labor Markets Workshop, Paris, 1-2 September.

Bhattacharya, P. (2007), "Informal sector, income inequality and economic development", CERT Discussion Papers, No. 709, Centre for Economic Reform and Transformation, September.

Boone, L. (2000), "Comparing semi-structural methods to estimate unobserved variables: the HPMV and Kalman filters approaches", OECD Economics Department Working Papers, No. 240, Paris, OECD Publishing.

Bosch, M. and W. Maloney (2010), "Comparative analysis of labor market dynamics using Markov processes: an application to informality", Labour Economics, vol. 17, No. 4, Amsterdam, Elsevier.

Calderón, A. (2000), "Job stability and labor mobility in urban Mexico: a study based on duration models and transition analysis", Research Network Working Paper, No. R-419, Washington, D.C., Inter-American Development Bank (IDB).

Chagny, O. and M. Lemoine (2002), "The impact of the macroeconomic hypothesis on the estimation of the output gap using a multivariate Hodrick-Prescott filter: the case of the Euro area", paper presented at the Colloquium on Modern Tools for Business Cycle Analysis (28-29 November).

Chavarín, R. (2001), "El costo del desempleo medido en producto. Una revisión empírica de la ley de Okun para México", El Trimestre Económico, vol. 68, No. 270, Mexico City, Fondo de Cultura Económica, April-June.

Contreras, O. (2000), "Los estudios acerca de la flexibilidad laboral en México: algunas observaciones críticas", Estudios Sociológicos, vol. 18, No. 3, Mexico City, El Colegio de México.

Courtney, H. (1991), "Okun's law and business cycle in the Beveridge curve and Okun's law: a re-examination of fundamental relationships in the United States", thesis, Cambridge, Massachusetts, Massachusetts Institute of Technology (MIT), unpublished.

Crespo, J. (2003), "Okun's law revisited", Oxford Bulletin of Economics and Statistics, vol. 65, No. 4, Wiley.

De la Garza, E. (n/d), "La flexibilidad del trabajo en México", unpublished [online] http://sgpwe.izt.uam.mx/ pages/egt/publicaciones/articulos/flexibilidad.pdf.

Dell'Anno, R. and O. H. Solomon (2008), "Shadow economy and unemployment rate in USA: is there a structural relationship? An empirical analysis", Applied Economics, vol. 40, No. 19, Taylor \& Francis.

Diebold, F. and G. Rudebusch (1999), "Measuring business cycles: a modern perspective", Business Cycles: Durations, Dynamics and Forecasting, Princeton, Princeton University Press.

Engel, C. and J. D. Hamilton (1990), "Long swings in the dollar: are they in the data and do markets know it?", The American Economic Review, vol. 80, No. 4, Nashville, Tennessee, American Economic Association.

Filardo, A. (1994), "Business-cycle phases and their transitional dynamics", Journal of Business and Economic Statistics, vol. 12, No. 3, Taylor \& Francis.

Fleck, S. and C. Sorrentino (1994), "Employment and unemployment in Mexico's labor force", Monthly Labor Review, vol. 117, No. 11, Washington, D.C., Bureau of Labor Statistics.

Ford, R. and D. Rose (1989), "Estimates of the NAIRU using an extended Okun's law", Working Paper, No. 89-3, Ottawa, Bank of Canada.

Funkhouser, E. (1997), "Mobility and labor market segmentation: the urban labor market in El Salvador", Economic Development and Cultural Change, vol. 46, No. 1, Chicago, The University of Chicago Press.

Galli, R. and D. Kucera (2003), "Informal employment in Latin America: movements over business cycle and the effects of worker rights", Discussion Paper, No. DP/145/2003, Geneva, International Institute for Labour Studies (IILS).

Gil, I., C. Montenegro and D. Dömeland (eds.) (2002), Crafting Labor Policy: Techniques and Lessons from Latin America, Washington, D.C., World Bank.

Goldberg, P. and N. Pavcnick (2003), "The response of the informal sector to trade liberalization", NBER Working Paper, No. 9443, Cambridge, Massachusetts, National Bureau of Economic Research (NBER). 
Gong, X., A. van Soest and E. Villagomez (2004), "Mobility in the urban labor market: a panel data analysis for Mexico", Economic Development and Cultural Change, vol. 53, No. 1, Chicago, The University of Chicago Press.

González Anaya, J. (2002), "Labor market flexibility in thirteen Latin American countries and the United States: revisiting and expanding Okun coefficients", Working Paper, No. 136, Stanford, Stanford University, June.

Gordon, R. J. (1984), "Unemployment and potential output in the 1980s", Brookings Papers on Economic Activity, No. 2, Washington, D.C., Brookings Institution.

Guerrero, V. M., A. Islas and R. L. L. Ramírez (2017), "Trend estimation of multivariate time series with controlled smoothness", Communications in Statistics - Theory and Methods, vol. 46, No. 13, Taylor \& Francis.

Harris, R. and B. Silverstone (2001), "Testing for asymmetry in Okun's law: a cross-country comparison", Economics Bulletin, vol. 5, No. 2.

Harvey, A. C. (1989), Forecasting, Structural Time Series and the Kalman Filter, Cambridge, Cambridge University Press.

Heckman, J. and C. Pagés-Serra (2000), "The cost of job security regulation: evidence from Latin American labor markets”, Economía, vol. 1, No. 1, Washington, D.C., Brookings Institution Press.

Hodrick, R. J. and E. C. Prescott (1997), "Postwar U.S. business cycles: an empirical investigation", Journal of Money Credit and Banking, vol. 29, No. 1, Ohio, Ohio State University Press.

_ (1981), "Post-war U.S. business cycles: an empirical investigation", Discussion Paper, No. 451, Evanston, Illinois, Northwestern University.

Islas, A. and W. W. Cortez (2013), "An assessment of the dynamics between the permanent and transitory components of Mexico's output and unemployment", CEPAL Review, No. 111 (LC/G.2597-P), Santiago, Economic Commission for Latin America and the Caribbean (ECLAC).

Jardin, M. and G. Stephan (2011), "How Okun's law is non-linear in Europe: a semi-parametric approach", May [online] http://euroframe.org/files/user_upload/euroframe/docs/2011/EUROF11_Jardin_Stephan.pdf.

Laxton, D. and R. Tetlow (1992), "A simple multivariate filter for the measurement of potential output", Technical Report, No. 59, Bank of Canada.

Lee, J. (2000), "The robustness of Okun's law: evidence from OECD countries", Journal of Macroeconomics, vol. 22, No. 2, Amsterdam, Elsevier.

Maloney, W. (1998), "Are labor markets in developing countries dualistic?", Policy Research Working Paper, No. 1941, Washington, D.C., World Bank.

Martin, G. (2000), "Employment and unemployment in Mexico in the 1990s", Monthly Labor Review, Washington, D.C., Bureau of Labor Statistics, November.

Moosa, I. A. (1997), "A cross-country comparison of Okun's coefficient", Journal of Comparative Economics, vol. 24, No. 3, Amsterdam, Elsevier.

Okun, A. M. (1962), "Potential GNP: its measurement and significance", Proceedings of the Business and Economics Statistics Section, Alexandria, American Statistical Association.

Oliveira, A. (2002), "Are Mexican business cycles asymmetrical?", IMF Working Paper, No. 02/150, Washington, D.C., International Monetary Fund (IMF), September.

Prachowny, M. (1993), "Okun's law: theoretical foundations and revised estimates", The Review of Economics and Statistics, vol. 75, No. 2, Cambridge, Massachusetts, The MIT Press.

Rodríguez-Oreggia, E. (2007), "The informal sector in Mexico: characteristics and dynamics", Social Perspectives, vol. 9, No. 1, Autonomous University of Nuevo León.

Silvapulle, P., I. A. Moosa and M. J. Silvapulle (2004), "Asymmetry in Okun's law", The Canadian Journal of Economics, vol. 37, No. 2, Wiley.

Tokman, V. (2011), "Informalidad en América Latina: balance y perspectivas de políticas", Realidad, Datos y Espacio. Revista Internacional de Estadística y Geografía, vol. 2, No. 3, Aguascalientes, National Institute of Statistics and Geography (INEGI).

Vuletin, G. (2008), "Measuring the informal economy in Latin America and the Caribbean", IMF Working Paper, No. 08/102, Washington, D.C., International Monetary Fund (IMF). 